\title{
CORRIGENDUM
}

\section{Human parasites in the Roman World: health consequences of conquering an empire - CORRIGENDUM}

\author{
PIERS D. MITCHELL
}

doi:10.1017/S0031182015001651, Published online by Cambridge University Press, 8 January 2016

On page 56, in the left-hand column, there is an error in the following sentence: "After considering possible explanations, it seems plausible that the Roman enthusiasm for the fermented fish sauce known as garum may have acted as a method where fish tapeworm eggs could have been transported large distances across the empire and then be consumed without being subjected to cooking."

The phrase "fish tapeworm eggs" is to be replaced by "fish tapeworm larvae".

As corrected, it will read: "After considering possible explanations, it seems plausible that the Roman enthusiasm for the fermented fish sauce known as garum may have acted as a method where fish tapeworm larvae could have been transported large distances across the empire and then be consumed without being subjected to cooking."

REFERENCE

Piers D. Mitchell (2016). Human parasites in the Roman World: health consequences of conquering an empire. Parasitology, 144, Special Issue, 48-58. 